\title{
A ÚLTIMA DISCIPLINA DA ADMINISTRAÇÃO: UM ESTUDO DIDÁTICO E INTEGRADO DE UM MODELO DE PLANEJAMENTO ESTRATÉGICO
}

\author{
The last discipline of Management: \\ a didactic study integrated \\ from a Strategic plan model
}

Envio 18.04.08 / Aceite 27.07.08

\section{Carlos Alberto Gonçalves ${ }^{1}$ \\ Daniela Ferro Oliveira ${ }^{2}$}

\begin{abstract}
Resumo
No ensino de Administração, nos últimos períodos, geralmente existe em seus currículos de cursos a disciplina de Planejamento Estratégico e/ou de Política e Administração Estratégica. No sentido amplo, é uma disciplina desafiadora e de grande responsabilidade por exigir análises sobre o enorme conjunto de conhecimentos sobre os ambientes e atores constitutivos da empresa analisada. No âmbito das empresas, há a prática, por algumas corporações, de se adotar as atividades de "fazer o Planejamento Estratégico" como forma de reflexão, direcionamento e melhoria de racionalidade na pragmática da Gestão Estratégica. Esse trabalho aborda, como ênfase, uma proposta de elaborar um formato ou esboço de orientação à elaboração de Planejamento Estratégico (PE). Para isso, busca consorciar um modelo (frame) como base, proposto por Hitt, Ireland e Hoskisson (2002), e realizar uma bricolagem de ferramentas de suporte descritas por vários autores e espalhadas pela literatura. Discute-se, ainda, a riqueza de representação dos frames como forma disciplinadora da abstração humana (MILLER, 1956). Busca-se, com isso, não somente auxiliar no ensino da disciplina de PE, mas também oferecer aos executivos e consultores, na coordenação empresarial, elementos para a melhoria das atividades do "fazer o Planejamento Estratégico".
\end{abstract}

Palavras-chave: Planejamento Estratégico; Modelos; Gestão.

${ }^{1}$ Professor, Dr., CEPEAD/FACE/UFMG.

${ }^{2}$ Mestrando do Curso de Mestrado em Adm. CEPEAD/FACE/UFMG.

Rev. Adm. UFSM, Santa Maria, v. 1, n. 2, p. 225-240, mai./ago. 2008 


\begin{abstract}
In the teaching of the Management area, there is usually, in the last periods, the subject of Strategic Planning and/or Politics and Strategic Management. In a wide respect, it is a challenging subject and with great responsibility because it demands analyzes of a large group of the knowledge about the environment and analyzed company constitutive actors. In the setting of the companies there is a practice, of some corporations, in following the activities of 'doing the Strategic Planning' as a form of reflection, orientatation and rationality improvement in the Strategic Management pragmatic. This work approaches, mainly, a proposal to elaborate a guidance outline the development of Strategic Planning (SP). Thus, the association of a model (frame) as essential part, proposed by Hitt, Ireland and Hoskisson (2002), and the accomplishment of a bricolage to support tools described by several authors and dispersed in literature were explored. The wealth of the frames representation as disciplinarian form of the human abstraction are still discussed (MILLER, 1956). The propose with this work is not only to aid in the teaching of the discipline of SP, but also to offer executives and consultant, in the managerial coordination, tools for the improvement of the activities of 'doing the Strategic Planning'.
\end{abstract}

Keywords: Strategical Planning; Framework; Management.

\title{
1 Introdução
}

A atual comunidade comercial mundial está marcada por palavras-chave e de ordem, refletindo as mudanças sociais, tecnológicas, ideológicas e de consumo como: comércio eletrônico, Internet, competição, globalização e, em administração, uma das mais importantes, estratégia (GONÇALVES, REIS e GONÇALVES, 2001). Agir estrategicamente significa, hoje, para as empresas, adotar ações para competir e obter retornos acima da média (HITT, IRELAND e HOSKISSON, 2002). A literatura ainda discute muito a questão da vantagem competitiva sustentável, a qual, para esses autores e para Porter (1990), é atingida assim que essa vantagem se torna de difícil imitação ou reprodução e agrega valor. Portanto, nada mais razoável e seguro do que realizar um determinado planejamento estratégico e inserir a empresa no contexto global com certo controle dos riscos envolvidos.

Além disso, apesar da prática efetiva cotidiana da Gestão Estratégica visar à dinâmica das organizações, advindas dos eventos constitutivos dos mercados competitivos, há várias empresas que ainda praticam, com alguma regularidade, o seu Planejamento Estratégico (PE). Reconhece-se que o PE se faz necessário, principalmente nas grandes empresas com inúmeros projetos, grande quadro de pessoal com competências diversificadas e mix de produtos, dentre outros. Nos setores de elevada competição, com mudanças já rotinizadas por grandes eventos anuais em sazonalidades, tem-se observado a baixa utilização do PE no que tange à sua formatação apenas documental. Mesmo para as empresas em setores de elevada competição o Planejamento Estratégico tem sido aplicado como instrumento de melhoria da racionalidade da Gestão Estratégica e vice-versa.

Revisitando várias empresas, percebe-se, ainda, a prática das reuniões em hotéis, telefones celulares desligados, onde grupos de dirigentes se reúnem para elaborarem o Planejamento Estratégico da Empresa. Nessa atividade, imaginam que a dinâmica competitiva dos setores ficará estática enquanto fazem o seu PE. Percebe-se claramente que muitas empresas, principalmente as de grande porte, têm incorporado essa pragmática à sua rotina anual de atividades - mostrando que o "o PE está vivo". Nesse PE são alocadas lógicas de ações para o 
futuro, contingências, parcerias, recursos a serem distribuídos funcionalmente, e é comum se ouvir que isso está ou não está previsto ou orçado e planejado.

Vários autores apresentam modelos (frames) orientadores aos dirigentes com o intuito de orientar a construção do Processo de Administração Estratégica (KOTLER, 2000; HITT, IRELAND e HOSKISSON, 2002; SERRA, TORRES e TORRES, 2004; AAKER, 2001).

No desenvolver do trabalho, é justificada a escolha do modelo de Hitt, Ireland e Hoskisson (2002), comparativamente ao de Aaker (2001) em razão de amplitude, elementos constitutivos e sugestiva capacidade de generalização.

O estudo analisa os referidos modelos de PE com uma perspectiva didática e teórica, identificando e posicionando algumas das principais "ferramentas" conhecidas na literatura, dentro do modelo, como forma de criar facilidades de interpretação e racionalidade. Essa é a dimensão inédita deste trabalho, pois a maioria dos autores apresenta as ferramentas separadas do modelo de maior abstração, não estabelecendo vínculos entre eles.

O elenco de ferramentas a ser estudado para compor o modelo maior é: Análise ESTAP e Diamante, Matriz BCG - da Boston Consulting Group - a técnica de Balanced Scorecard (BSC), de Kaplan e Norton (1997), a ferramenta de Fatores Críticos de Sucesso na Matriz EFE (FCS), Análise SWOT ou FOFA, Cadeia de Valor e Cinco Forças, Curva de Aprendizagem e de Experiência, Curva do Ciclo de Vida dos Produtos, Alianças Estratégicas e Curva S e Curva M.

Este trabalho está estruturado na apresentação do modelo de Hitt, Ireland e Hoskisson (2002) como frame de referência, na exposição das ferramentas escolhidas para apoio ao pensamento estratégico e justificativa das ações sobre o modelo referência, na proposição do modelo revisado e nas conclusões e recomendações.

\section{Marco teórico do estudo}

Estratégia pode ser definida como um plano ou padrão a ser desenvolvido, especialmente a longo prazo. A estratégia, a partir da análise dos livros mais clássicos ao seu respeito (OHMAE, 1982; MINTZBERG, 2004; PORTER, 1986, RIES e TROUT, 1986), pode ser definida de uma maneira muito simples: conjunto de elementos e procedimentos que garantam a sobrevivência e o desenvolvimento da organização em longo prazo.

Neste contexto, entra o Planejamento Estratégico, o qual tem se tornado atualmente um modismo - apesar de realmente essencial. Mintzberg (2004) indaga o porquê de se planejar. Uma vez que prever o futuro é praticamente impossível, planeja-se levando em conta as variáveis envolvidas no negócio da empresa. Este mesmo autor afirma que, algumas vezes, a fase de planejamento da empresa pode ser tão superficial que seus idealizadores preocupam-se mais com ideais vagos do que encontrar posições viáveis para o projeto.

Planejar pode significar pensar no futuro; tentar até controlá-lo; tomar decisões, integradas ou não. Mintzberg (2004) cita todas essas possibilidades, e pode-se inferir que o planejamento está intimamente relacionado ao possível sucesso futuro e que ele é imprescindível para a organização que deseja controlar melhor suas atividades.

Vários autores têm apresentado a forma de se conduzir um PE por meio, primeiramente, de uma seqüência de quadros semânticos interligados por arcos e setas. Inicialmente considerase que, ao mesmo tempo em que é útil, a abstração, se não orientada, torna-se o elemento mais anárquico na forma do pensar do ser humano. Como estratégia é, muitas vezes, tratada como um recurso polissêmico, apresentando várias formas de se dirigir o pensamento para diferentes contextos, o uso de frames disciplinadores torna-se fundamental. Além disso, o ensino e a pragmática da administração, embora lide com elementos concretos como pessoas, 
processos materiais etc., têm uma forte componente abstrata, que são formatos de gestão. Assim, uma ampla utilização de frames tenta "concretizar" e apoiar o disciplinamento da abstração, atribuindo uma lógica estrutural como uma forma de caminhamento de algum tipo de "objeto" em fluxo ou de interpretação. Um dos autores de Inteligência Artificial, que tratou dos usos de Quadros como referência de apoio ao fluxo de abstrações disciplinadora da cognição foi Marvin Minsky (1975, p. 104), no artigo "A Framework for Representing Knowledge". Nesse artigo, ele discute amplamente a forma de usar frames como esquema para apoiar a cognição, comentando que,

um frame é uma estrutura de dados para representar uma situação estereotipada, tal como estar em um certo tipo de sala de estar, ou ir a uma festa de aniversário de criança. Anexado a cada frame estão vários tipos de informação. Algumas dessas informações são sobre como utilizar o frame. Algumas são sobre o que as pessoas podem esperar que vá acontecer. Algumas são sobre o que fazer caso estas expectativas não sejam confirmadas. Podemos considerar um frame como uma rede de interrelações. (Tradução dos autores)

Deve-se criticar o modo geral da representação do conhecimento através dos frames propostos pelos autores da área de Administração - possuem bem menos rigor que as plantas adotadas pelos engenheiros. Esses cuidam dos significados de cada elemento de uma representação, com legendas e direção dos fluxos de ações, informações. Considera-se que um dos poucos autores cuidadosos com os frames apresenta-se no contexto da análise da dinâmica das organizações propostas por Forrester (1997). Os frames apresentados, em geral, deveriam seguir uma analogia com os modelos de estruturação da linguagem segundo as dimensões de contexto (pragmática), a semântica, a sintaxe e o léxico. Via de regra, pecase já no léxico, pois não explicam o que significa os símbolos adotados por meio de legendas, nem apresentam orientação de direcionamento e sentido de ligação dos símbolos adotados, ferindo a lógica. Muitas vezes os símbolos em quadros têm significados ambíguos, prejudicando a semântica. A visão integrativa, global do frame, apresenta-se sem um contexto em que mostre sua validade contextual, prejudicando a sua ligação e funcionalidade com pragmáticas, criandose o heteromorfismo do modelo com os campos de aplicação.

No caso de Administração, diz-se que o frame deverá: a) ter consistência estética; ter uma representação de fácil leitura e interpretação pelos seus leitores de forma não ambígua e superando subjetividades; b) ser gestáltico e cartesiano, ao mesmo tempo em que permita a visão do todo, deve permitir alguma fragmentação funcional para interpretação e implementação de ações; c) ter aderência, representando e capturando de forma adequada a pretensa realidade que modela.

\subsection{O modelo proposto por Hitt, Ireland e Hoskisson (2002)}

O modelo (frame), proposto por Hitt, Ireland e Hoskisson (2002), abrange três fases do processo de administração estratégica: 1) insumos e informações estratégicas; 2) ações estratégicas propriamente ditas; e 3) resultados estratégicos. O processo tem, ainda, a fase de feedback, na qual as informações agregadas ao final retornam para auxiliar um novo ciclo.

O processo demonstrado na Figura 1 mostra um conjunto completo de compromissos, decisões e ações necessárias para que uma organização consiga competir estrategicamente e tenha retornos superiores à média.

Todo o processo tem início com os inputs gerados pelos insumos de informações estratégicas (que são os ambientes externo e interno e a Intenção e Missão Estratégicas),

Rev. Adm. UFSM, Santa Maria, v. 1, n. 2, p. 225-240, mai./ago. 2008 
culminando na formulação e implementação da estratégia, que formam a fase de ações estratégicas. Essas são as condições indispensáveis para obter os resultados desejados na competitividade estratégica e nos retornos financeiros.

Primeiramente, será feita a descrição de cada fase e ação estratégica inserida no modelo da Figura 1, para a posterior apresentação das ferramentas estratégicas e suas relações com o modelo de Hitt, Ireland e Hoskisson (2002).

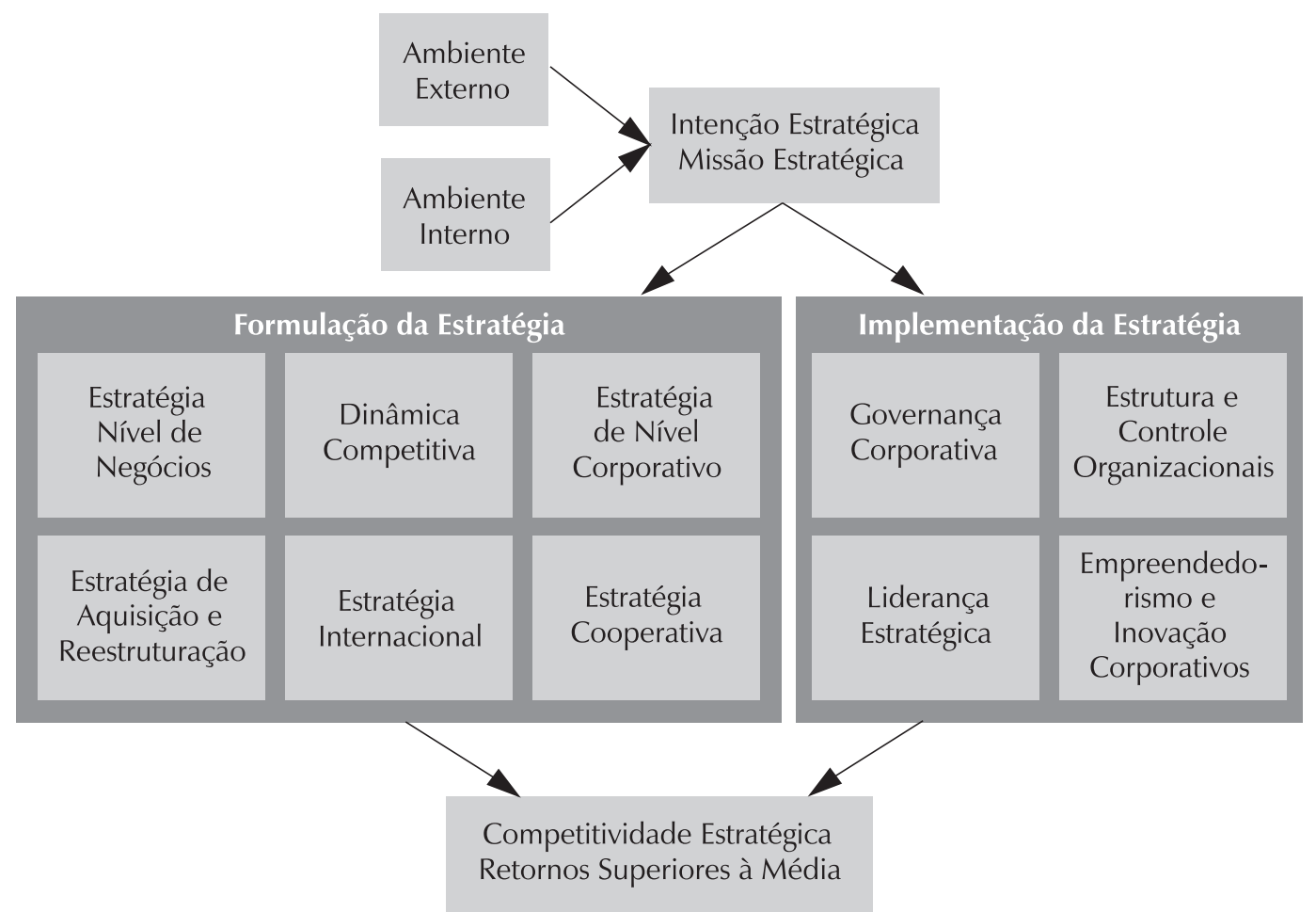

Figura 1 - Processo de Administração Estratégica. Fonte: modelo adaptado de Hitt, Ireland e Hoskisson (2002).

Em um primeiro momento, analisando-se o modelo da Figura 1, percebe-se que os ambientes externo e interno influenciam diretamente a Intenção e Missão Estratégicas.

O ambiente externo, segundo Hitt, Ireland e Hoskisson (2002), possui influência sobre as opções estratégicas de uma organização e suas decisões. Baseada nas novas informações, conhecimentos e capacidades, sobre concorrentes, clientes e outros stakeholders, a empresa garante o desenvolvimento de uma vantagem competitiva e adota medidas para reduzir o efeito do impacto ambiental.

Combinado com o ambiente externo, o ambiente interno auxilia na formulação da Intenção e Missão Estratégicas, que, por sua vez, colaboram na busca pela competitividade estratégica. Analisando-se a empresa internamente, percebe-se que ela própria determina o que poderá fazer com os recursos, capacidade e competências que possui. As decisões, segundo Hitt, Ireland e Hoskisson (2002), tomadas pelos gestores em termos daqueles fatores, influenciam significativamente a habilidade da organização em desenvolver e sustentar vantagens competitivas e adquirir retornos superiores à média.

Para Hitt, Ireland e Hoskisson (2002), a Intenção Estratégica é o ato de impulsionar e dirigir os recursos internos e as competências essenciais de uma empresa, com a finalidade de cumprir as metas em uma atmosfera competitiva. Combinando os recursos adequadamente, 
ela é capaz de gerar um desempenho de maneiras inimagináveis, e só terá sido constituída apropriadamente quando todas as pessoas envolvidas acreditarem na empresa e em seu desempenho.

Já a Missão Estratégica, diferentemente da Intenção, a qual está orientada para o ambiente interno, é uma declaração dos objetivos de alcance de mercado de uma organização (HITT, IRELAND e HOSKISSON, 2002). Kotler (2000) afirma que a missão da empresa deve ser compartilhada com gerentes, funcionários e clientes, gerando um senso comum de propósito, oportunidade e direção. A Intenção, juntamente com a Missão Estratégica, determina o discernimento exigido para criar e implementar as estratégias da organização.

Na segunda fase, proposta pelos autores Hitt, Ireland e Hoskisson (2002), a formulação e implementação de estratégias devem ocorrer simultaneamente, como mostra a seta dupla entre esses dois grandes grupos de ações (Figura 1). A Estratégia no Nível de Negócios é um conjunto integrado de ações e compromissos, que tem por finalidade gerar valor para os clientes e atingir uma vantagem competitiva, utilizando competências em mercados de produtos específicos e individuais. Hitt, Ireland e Hoskisson (2002, p. 146) ainda afirmam que "o cliente é o alicerce das estratégias no nível de negócios bem-sucedidas".

Já a Dinâmica Competitiva pode ser encontrada quando há uma série de ações e reações entre empresas competindo dentro de uma indústria determinada. As organizações devem estar atentas para os movimentos dos concorrentes e para as exigências dos clientes. Dessa forma, torna-se cada vez mais importante inovar e investir em qualidade.

Enquanto a Estratégia de Nível de Negócios diz respeito a ações basicamente competitivas, a Estratégia de Nível Corporativo abrange a empresa inteira. Ela pretende ganhar vantagem competitiva por meio da escolha e gestão de um conjunto de negócios que competem em diversos mercados (HITT, IRELAND E HOSKISSON, 2002).

As Estratégias de Aquisição e Reestruturação estão ligadas à compra de participação em uma empresa por outra, no primeiro caso, e à modificação do seu conjunto de negócios ou estrutura financeira, no outro caso.

A Estratégia Internacional leva em conta a venda de produtos em mercados fora daquele doméstico de uma organização. A possibilidade de novas oportunidades e a globalização impulsionam este tipo de estratégia.

As Estratégias Cooperativas podem ser em forma de alianças estratégicas, uma forma de dividir esforços com outras empresas, combinando recursos e capacidades únicos para criar competências essenciais de difícil imitação para os concorrentes.

$\mathrm{Na}$ parte da implementação da estratégia, inicia-se estudando a Governança Corporativa. Ela representa a relação entre os investidores, a qual determina e controla a direção estratégica e o desempenho das organizações. Ela também se preocupa para que as decisões sejam tomadas eficientemente. Ela reflete os valores de organização, estabelecendo certa ordem entre os proprietários e os gerentes.

Para Hitt, Ireland e Hoskisson (2002, p. 443), “escolher a Estrutura e Controle Organizacionais que implementam de maneira eficiente as estratégias escolhidas é um desafio fundamental para os gerentes". A estrutura é a configuração formal dos procedimentos da empresa, a qual pode ser simples, funcional ou multidivisional, segundo os autores.

A Liderança Estratégica antecipa e mantém flexibilidade e delega poderes para criar mudança estratégica quando necessário. Ela envolve administrar por meio de outros e lidar com mudanças. Preocupa-se com o desenvolvimento do capital humano e com a cultura organizacional, influenciando os negócios empresariais.

Por último, o Empreendedorismo e Inovação Corporativa fecham a fase de Implementação. A Inovação cria, gera novas idéias. O Empreendedorismo corporativo desenvolve 
a Inovação na organização. Tudo isso afeta os esforços da empresa em obter competitividade estratégica e ganhar retornos acima da média.

\subsection{Análise de organizações, modelo de Aaker (2001)}

O modelo proposto por Aaker (2001) pode ser utilizado com a finalidade de identificar e posicionar os componentes da empresa e suas integrações. O esquema (Figura 2) tem como eixo principal quatro construtos-chave: estrutura, sistemas, pessoas e cultura.

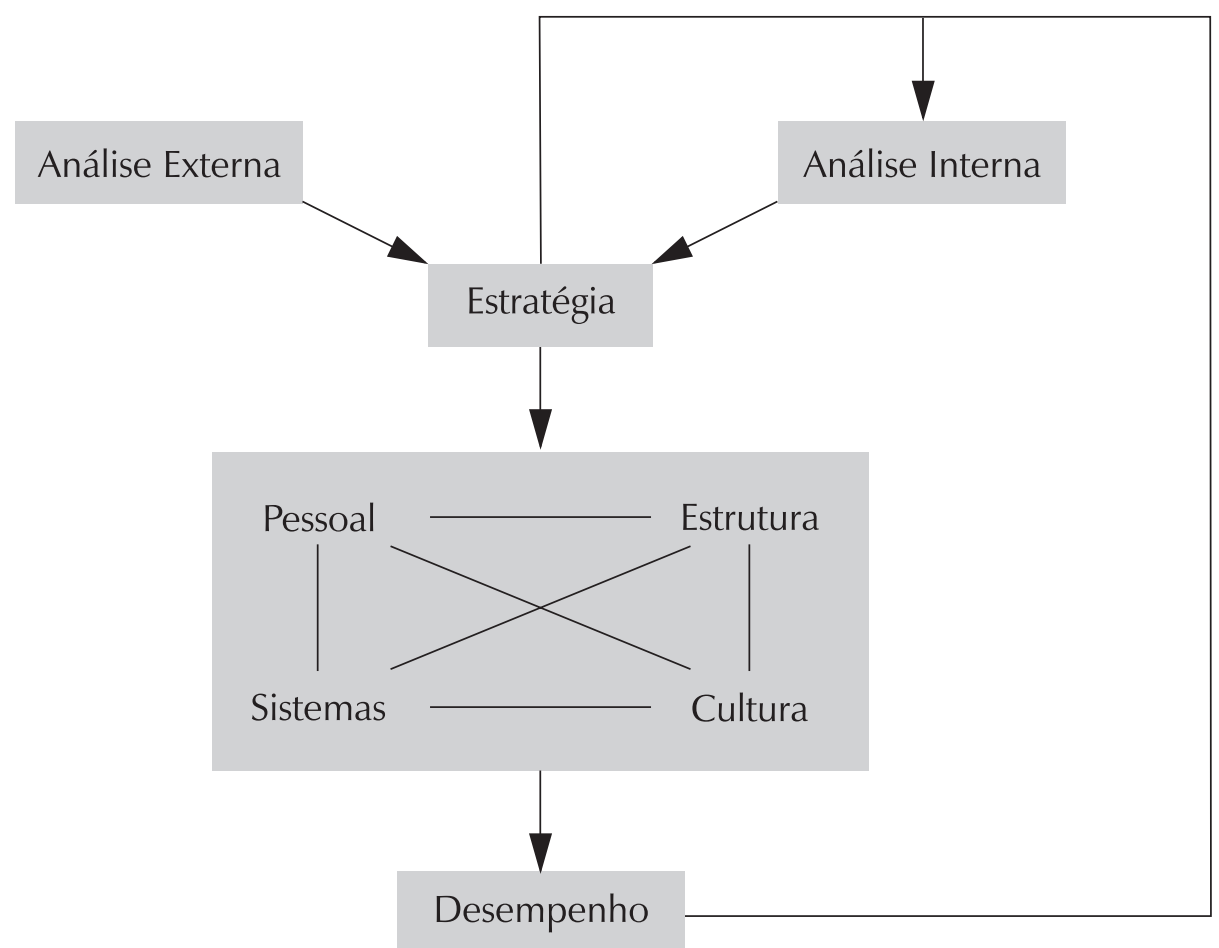

Figura 2 - Quadro Teórico para Análise de Organizações. Fonte: Aaker (2001).

Pode-se observar que o modelo inclui, assim como o de Hitt, Ireland e Hoskisson (2002), a análise dos ambientes externo e interno da empresa, mostrando que o modelo de Aaker (2001) pode ser estudado conjuntamente com o da Figura 1.

Além disso, a dimensão estrutura está presente nos dois modelos, percebendo-se que o modelo de Hitt, Ireland e Hoskisson (2002) mostra-se muito mais elaborado que o de Aaker (2001). Ambos terminam em uma avaliação do desempenho das estratégias realizadas pela organização. Da mesma forma, as dimensões do eixo principal de Aaker (2001) estão estreitamente ligadas, como também estão as fases de formulação e implementação da estratégia do modelo da Figura 1.

Infere-se, portanto, que o modelo de Aaker (2001) pode ser considerado como um frame levemente reduzido daquele de Hitt, Ireland e Hoskisson (2002), diferindo principalmente nas dimensões Pessoal e Cultura.

Aaker (2001) valoriza também a competência organizacional das pessoas, as quais contribuem para as empresas com suas atitudes, experiências e habilidades. O autor enfatiza também a questão da motivação e estimulação de desafios nos empregados.

A Cultura, para os dois autores, é um conjunto de valores, normas de comportamento e símbolos que as nutrem, e está bem delineada no modelo de Aaker (2001). Já para Hitt, Ireland 
e Hoskisson (2002, p. 505), ela se encaixa no estudo da Liderança Estratégica, afirmando que "modelar o contexto dentro do qual a firma formula e implementa suas estratégias - ou seja, modelar a cultura organizacional - é tarefa fundamental dos líderes estratégicos".

\section{Ferramentas de apoio à análise, projeto e implementação do Planejamento Estratégico}

Na elaboração do Planejamento Estratégico, os grupos de trabalho aplicam várias ferramentas de diagnóstico e análise que não devem aparecer no documento final resultante do trabalho. Elas são adotadas como instrumentos de análise e síntese e, no documento final, apresentam-se os macroitens como: Descrição do Negócio, Visão, Missão, Principais Valores, Objetivos Gerais de Crescimento, Metas Gerais (quantificadas) e seus Desdobramentos em Ações Funcionais (Marketing, Finanças, Pessoal, Produção).

Para o leitor final do PE, não aparece o uso de ferramentas como BCG, BSC, FCS dentre outras. Esses formatos "ficam na gaveta", como documentos a serem recuperados se necessário, como memória auxiliar dos procedimentos que foram executados para se chegar ao PE final. Esse PE pode ser mostrado ao público, aos acionistas da empresa e, evidentemente, sua publicação em detalhes pode revelar dimensões estratégicas que podem revelar informações para a concorrência e comprometer a competitividade da empresa.

\subsection{Análise ESTAP e Diamante}

Esse conjunto de análises compreende todo um conjunto de estudos sobre indicadores e tendências nas macrodimensões da Economia, Social, Tecnologia, impactos Ambientais, Política - ESTAP (QUICKMBA, 2004). Um brainstorming inicial feito pelo grupo dirigente assistido por especialistas pode promover um cenário do ambiente em que a empresa estará imersa. Nessas grandes dimensões ocorrem indicadores da massa salarial dos segmentos, tendências de comportamento de classes sociais, ideologias sobre impactos ambientais, dependências tecnológicas, mudanças políticas adotadas pelo governo, estabilidade e confiabilidade nos contratos, dentre outros. Essa análise, certamente, poderá fornecer subsídios para outras, como a SWOT. Nessa linha, pode-se incluir o Diamante de Porter, segundo Hitt, Ireland e Hoskisson (2002, p. 326) - Determinantes de Vantagem Nacional, compreendendo as quadro dimensões: Fatores de Produção, Condições de Demanda, Indústrias Relacionadas de Apoio e Estratégia, Estrutura e Rivalidade da Firma. Essa ferramenta de análise é útil ao diagnóstico para a entrada (ou saída) em setores e internacionalização.

\subsection{Matriz BCG}

Considerada útil na análise de portfólio de produtos e posicionamento no ambiente externo, a abordagem do Boston Consulting Group tornou famosa a matriz de crescimento/ participação, a popular Matriz BCG.

Desenvolvida pelo grupo líder em consultoria de gestão, a matriz relaciona a taxa de crescimento do mercado, no eixo vertical, com a participação relativa de mercado, no eixo horizontal. É, portanto, um modelo apresentado em um gráfico de quadrantes (KOTLER, 2000), e quatro grandes posições podem surgir: pontos de interrogação, estrelas, vacas leiteiras e animais de estimação (Figura 3). 


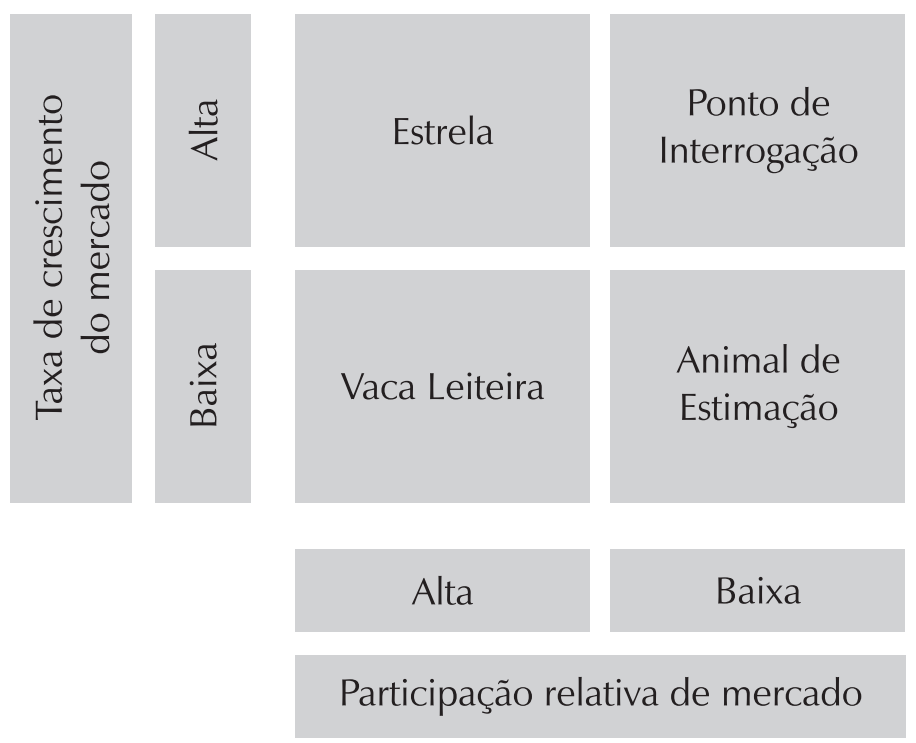

Fonte: Kotler (2000).

Figura 3 - Matriz de Crescimento/Participação - BCG.

A matriz pretende calcular a taxa de crescimento do mercado através do uso do caixa financiando o capital de giro. A participação relativa de mercado, por sua vez, é calculada a partir da razão entre as vendas do produto da empresa e as vendas do produto concorrente de maior venda no segmento de mercado considerado.

Começa-se analisando pelos Pontos de Interrogação. Estes são negócios que operam em mercados de alto desenvolvimento, porém com baixas participações relativas. Esta fase requer muitos investimentos para acompanhar o alto crescimento em direção à posição de líder do mercado. Já a fase de Estrelas é atingida assim que o negócio de Ponto de Interrogação tornar-se bem-sucedido. Esta fase é a líder em mercados de alto crescimento, apesar de não possuir substancialmente um fluxo de caixa positivo.

Segundo Kotler (2000), a taxa de crescimento de mercado pode cair bastante, mas se o negócio ainda detiver a participação relativa mais alta naquele setor, a Estrela torna-se uma Vaca Leiteira. Esta fase é onde o negócio gera muito caixa e goza de maiores margens de lucro.

Os Animais de Estimação, como mostrado na Figura 3, são aqueles negócios com baixas participações nos mercados de pouco crescimento. Podem gerar até prejuízos, e estão fortemente ligados às questões sentimentais.

Verificando agora a Matriz BCG com relação ao modelo do Processo de Administração Estratégica de Hitt, Ireland e Hoskisson (2002), nota-se que o primeiro modelo está intimamente ligado na parte de Estratégia no Nível de Negócios do segundo, quando se analisam as estratégias de liderança em custo e diferenciação dos negócios, levando em conta a participação no mercado e seu crescimento. A Matriz BCG é, portanto, essencial para avaliar a viabilidade e a possibilidade de ascensão - ou queda - de cada negócio.

\subsection{Balanced Scorecard (BSC)}

As últimas décadas vêm assistindo a novos conceitos referentes à organização moderna, como, por exemplo, Just-in-time, Produção focada no cliente, Reengenharia etc., os quais traduzem as novas tendências do mercado. 
É nesse contexto que entra o principal diferencial do BSC: ele reconhece que utilizar apenas os indicadores financeiros para avaliar o desempenho de uma organização não é suficiente, uma vez que mostram somente resultados de investimentos e atividades, e não se importam com a rentabilidade e sucesso a longo prazo. Esta estratégia de medida se encaixa no perfil do mercado atual, já que procura medir o desempenho em várias dimensões, buscando o êxito.

O modelo tradicional de medida contábil não considera o ambiente altamente competitivo vivido hoje em dia pelas organizações. É preciso, segundo Kaplan e Norton (1997), que os aspectos intangíveis também possam entrar nos modelos de contabilidade financeira, apesar da sua dificuldade ser reconhecida. Apesar disso, o BSC deve preservar o foco nos resultados financeiros, pois as medidas financeiras serão fonte de resultados decisivos para mudanças nas organizações.

Seguindo esta lógica, o Balanced Scorecard (BSC) é uma ferramenta de gestão para medir o desempenho organizacional, abrangendo quatro dimensões: financeira, do cliente, dos processos internos da empresa e do aprendizado e crescimento (Figura 4). Foi criado por Robert Kaplan e David Norton, professores da Harvard Business School (KAPLAN e NORTON, 1997). É um instrumento que está intimamente ligado a questões estratégicas, objetivando auxiliar as empresas na obtenção de vantagens competitivas sustentadas.

À medida que a utilização do Balanced Scorecard é mais difundida, as organizações notam que ele pode ser usado para uma série de funções, tais como obter de um consenso em relação à estratégia adotada, obter de feedback para aprofundar o conhecimento, alinhar metas dos cargos hierarquicamente inferiores às dos cargos executivos, realizar contínuas revisões estratégicas etc.

É possível afirmar que o scorecard cria uma nova linguagem ao comunicar a missão e a estratégia à empresa, e o faz segundo os indicadores disponíveis, comunicando decisões atuais e futuras. É neste contexto que entra a principal finalidade do BSC: a canalização de habilidades e conhecimentos de todos os funcionários da empresa, a fim de atingir metas de longo prazo.

Suas perspectivas são interligadas. A Satisfação dos Clientes os retêm na organização e contribuem para melhorar a imagem da mesma; a dimensão de Processos Internos auxilia na busca e identificação dos processos críticos para se alcançar sempre a excelência nos negócios; a perspectiva de Aprendizado e Crescimento tem como base melhoria da qualidade e inovação, além de investimento nas competências dos empregados. Todas essas três perspectivas estão estreitamente direcionadas aos objetivos financeiros da organização, sendo a meta principal gerar retornos financeiros.

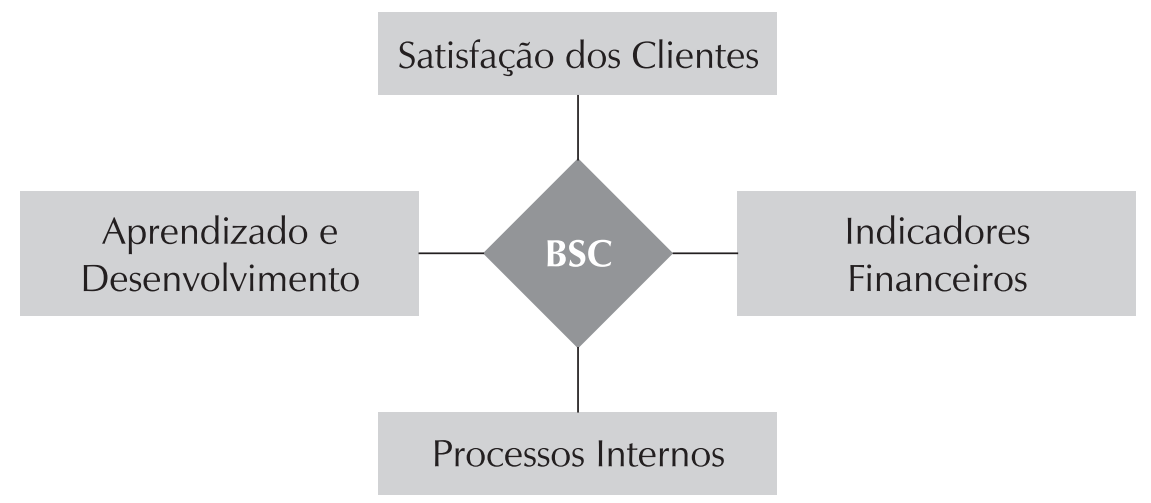

Fonte: SAS (2004).

Figura 4 - Perspectivas do BSC.

Rev. Adm. UFSM, Santa Maria, v. 1, n. 2, p. 225-240, mai./ago. 2008

$$
-234 \text { - }
$$


Analisando o frame do BSC (KAPLAN e NORTON, 1997) em conjunto com o de Hitt, Ireland e Hoskisson (2002), pode-se observar que a perspectiva de Aprendizado e Crescimento do BSC está relacionada com a fase de Empreendedorismo e Inovação Corporativos dos outros autores. Da mesma forma, a dimensão Processos Internos do primeiro modelo complementa a de Estrutura e Controle Organizacionais do segundo. A perspectiva de Satisfação dos Clientes associa-se à dimensão de Estratégia de Nível de Negócios, uma vez que está relacionada à segmentação de mercados e à constante busca por atender sempre às necessidades dos consumidores. Finalmente, a dimensão Indicadores Financeiros é a mais relevante tanto no BSC quanto no modelo de Processo de Administração Estratégica, na qual se buscam retornos superiores à média.

\subsection{Matriz de Avaliação de Fatores Externos (EFE - External Factor Evaluation)}

Esta é uma matriz que relaciona os Fatores Críticos de Sucesso (FCS) que colabora para a análise de diversos aspectos ambientais, culturais, econômicos, sociais, demográficos, tecnológicos, entre outros existentes no contexto no qual a organização está inserida (DAVID, 1998). Segundo Aaker (2001, p. 34), um FCS (ou Fator-Chave de Sucesso, como este autor o denomina), é um "ativo competitivo ou uma competência que é necessária para vencer em um mercado". Desenvolver estratégias, no entanto, necessita embasamento em difíceis decisões sobre quais serão os FCS de sucesso futuramente.

O Quadro 1 mostra como se deve montar a Matriz de Avaliação de Fatores Externos a partir da identificação dos FCS.

\begin{tabular}{|c|c|c|c|c|}
\hline \multicolumn{2}{|c|}{ Fatores Críticos de Sucesso } & Peso & Desempenho & Resultado \\
\hline \multirow{4}{*}{ Oportunidades } & Fator 1 & W1 & D1 & W1xD1 \\
\hline & Fator 2 & W2 & D2 & W2xD2 \\
\hline & ….............. & …................. & ...................... & ................. \\
\hline & ……........... & ……............ & ……............. & .................. \\
\hline \multirow{4}{*}{ Ameaças } & & …................. & …................ & ................... \\
\hline & & .. & $\cdots$ & \\
\hline & Fator n-1 & Wn-1 & Dn-1 & Wn-1xDn-1 \\
\hline & Fator $\mathrm{n}$ & Wn & Dn & WnxDn \\
\hline Somatório & & & & \\
\hline
\end{tabular}

Fonte: David (1998).

Quadro 1 - Matriz EFE.

Para prosseguir com a aplicação da Matriz EFE, há certos passos a serem seguidos:

a) deve-se, primeiramente, listar os Fatores Críticos de Sucesso (FCS) externos, das oportunidades às ameaças;

b) depois, deve-se determinar, para cada fator, um peso que varie de 0.0 (não importante) a 1.0 (muito importante). O peso indica a importância do fator no alcance de sucesso pela indústria; a soma dos pesos associados aos fatores deve ser igual a 1.0;

Rev. Adm. UFSM, Santa Maria, v. 1, n. 2, p. 225-240, mai./ago. 2008 
c) pontua-se cada FCS externo de 1 a 4, indicando como está a efetividade da organização respondendo ao fator: 4 - a resposta é superior, 3 - a resposta é acima da média, 2 - a resposta é média e 1 - a resposta é pobre;

d) multiplica-se cada peso pelo ponto recebido pelo fator na etapa anterior;

e) somam-se os resultados obtidos no passo anterior, obtendo o resultado total da organização; quanto mais alto este resultado, mais a organização aproveitará as oportunidades e reduzirá as ameaças.

Claro que esta mesma matriz pode ser também utilizada para analisar os fatores internos da empresa. Este estudo contribui para a consideração e verificação dos recursos disponíveis na organização. Isto está diretamente relacionado com a fase de análise dos ambientes externo e interno do modelo da Figura 1.

Já para os autores Bullen e Rockart (1981), o objetivo do método de FCS é elicitar os fatores componentes mais relevantes de um sistema. O princípio básico do processo é o de que o próprio usuário é capaz de definir suas necessidades de dados. O método, para eles, consiste das seguintes fases:

- Primeira fase e primeira reunião: (a) solicitar ao decisor (informante) que enuncie os principais Fatores Críticos de Sucesso para o desempenho funcional para o alcance de objetivos relativos ao seu negócio; (b) anotar os fatores e pedir ao informante que ordene os fatores do mais para o de menor importância;

- Segunda fase e segunda reunião: (a) pedir ao informante que enuncie novamente os Fatores Críticos de Sucesso; (b) pedir para ordená-los, como da primeira vez.

Bullen e Rockart (1981) sugerem, então, comparar as duas relações. Se as listas forem iguais, então os fatores foram enunciados com sucesso. Caso contrário, devem-se apresentá-las ao decisor e tentar ajustá-las.

Pode-se notar que a metodologia de Fatores Críticos de Sucesso é muito útil no início do processo de Planejamento Estratégico indicado na Figura 1, uma vez que define os objetivos e metas que a organização pretende atingir.

\subsection{Forças e Fraquezas, Ameaças e Oportunidades (SWOT ou FOFA)}

Esta é uma das mais famosas técnicas de direcionamento de abstrações para se elaborar PE (STERN e STALK JR., 2002). Nessa técnica há o direcionamento da visão do decisor segundo duas direções matriciais (espacialmente cartesianas). O eixo das abcissas olha para o externo, buscando os pontos de Ameaças e Oportunidades; no eixo das ordenadas, buscam-se os pontos de Forças e Fraquezas. Advoga-se sua prática para apoio ao PE e constata-se que realmente possui grande conteúdo informacional - que até confunde a síntese para direcionamento de decisão -. Em suas limitações, podem-se apontar os desafios de interpretação, pois é possível que haja oportunidades e ameaças internas ou forças e fraquezas do ambiente externo. Além disso, é preciso reforçar as fraquezas para aproveitar oportunidades ou evitá-las.

\subsection{Cadeia de Valor (CV) e Cinco Forças (5F)}

A Cadeia de Valor é um frame que apóia a análise e visão dos recursos e processos internos da empresa (PORTER, 1986). As cinco forças mostram uma competência de análise externa da empresa. O consórcio das duas técnicas pode apoiar o decisor no direcionamento 
de suas abstrações para as dimensões interna e externa da empresa e também no sentido do que fazer nas lógicas Inside Out (de dentro ver o que se pode fazer fora) e Outside In (de fora ver o que se pode fazer dentro). São frames ricos em informação para a dimensão analítica e trazem desconforto para a fase de síntese (o que fazer).

\subsection{Curvas de Aprendizagem e Experiência (CAE)}

Os estudos de Curva de Aprendizagem mostram como os custos totais da produção se reduzem com os ganhos de conhecimento das equipes. Ao lançar novos produtos a empresa deve se lembrar de que terá de aprender os processos, calibrar linhas de produção, negociar com novos fornecedores etc. (BETHELEN, 1999). A CA possui, em geral, o formato de uma hipérbole, descrita pela projeção em sua ordenada, os custos de produção e, em abcissa, o tempo. Certamente que enquanto se aprende incorre-se em custos e perdas indesejáveis. A concorrência sabe disso - podendo utilizar-se do momento para baixar preços e subjugar o novo entrante nos mercados que atua (GHEMAWAT, 2000). De forma parecida, a Curva de Experiência implica em redução de tarefas repetitivas e do tempo necessário para se produzir unidades. Segundo Stern e Stalk Jr., (2002), o custo do valor agregado cai cada vez que a experiência acumulada duplica em torno de 20 a 30\%. A curva é expressa nas ordenadas pelo preço final de oferta versus a quantidade acumulada da produção.

\subsection{Curva do Ciclo de Vida de Produtos - CCV}

A Curva do Ciclo de Vida do Produto possui, como muitos autores apresentam, o formato de uma "montanha" (parábola), representada, pelas ordenadas, o volume de produtos vendidos e, na abscissa, o tempo (BETHELEN, 1999). A curva torna-se pobre em informação se não for consorciada com outras variáveis como preços, giro, importância no mix, dentre outras. A curva compreende as fases que se chamam de Introdução, Crescimento, Maturidade e Declínio. O ciclo de vida dos produtos pode ser consorciado com a Matriz BCG para fornecer idéias das decisões sobre os portfólios de produtos.

\subsection{Alianças Estratégicas (AE)}

Hitt, Ireland e Hoskisson (2002) propõem ferramentas para justificar a necessidade de se propor alianças estratégicas. Uma delas é por tipo de comportamento de consumidores por mercados, ou seja, aqueles de Ciclo Lento, Ciclo Padrão, Ciclo Rápido. Os autores propõem tipos de Alianças em: (a) Nível de Unidades de Negócio - alianças complementares, para redução da competição, resposta à competição e redução de incerteza; e (b) Nível Corporativo - alianças por diversificação, sinérgicas e franquias.

\subsection{Curva S e Curva M - CS\&M (Governança Corporativa)}

Os autores Hitt, Ireland e Hoskisson (2002) propõem atenção aos dois tipos de risco de contratação de terceiros para a administração corporativa. Segundo os autores, a Curva $S$ diz respeito à opção de gestão pelos acionistas proprietários (ou investidores), com riscos em resultados e políticos, enquanto a $M$ significa a gestão por contrato de dirigentes nãoproprietários, com riscos de seus empregos e políticos. Assim, na curva S, os dirigentes deverão 
optar por minimização dos riscos e podem preferir focar em um negócio (economia de escala), aumentando a rivalidade do setor, ficando mais à retranca quanto à diversificação. Já na curva $\mathrm{M}$, os executivos, para reduzir risco de emprego, deverão buscar maior diversificação, tendendo à economia de escopo.

\section{Um modelo resultante}

O Quadro 2 mostra uma proposta para a aplicação das ferramentas citadas, no apoio à execução das análises das diversas fases do modelo do Hitt, Ireland e Hoskisson (2002). O número de técnicas não se esgota facilmente e escolheu-se aquelas que, de um modo geral, a literatura tem apontado.

Há, ainda, um número maior de técnicas de apoio, inclusive as de natureza mais funcional no plano interno e externo, no nível de Marketing, Finanças, Produção, Redes, que podem afetar o desempenho da estratégia e, conseqüentemente, merecem a atenção do decisor.

Assim, como resultante dos tópicos anteriores e da proposta de uso de técnicas do Quadro 2, propõe-se os seguintes tópicos ou capítulos para constituir o documento do PE de "Elementos Constitutivos do PE": (a) Descrição do Negócio; (b) Missão, Visão, Principais Valores Corporativos; (c) Estratégia Corporativa - Objetivos Gerais e Específicos em nível Corporativos, Principais Planos e Metas em nível Corporativo; (d) Estratégia de Negócios - Objetivos Gerais e Específicos em nível de Negócios, Principais Planos e Metas em Nível de Negócios; (e) Estratégia Internacional (se for o caso); (f) Planos de Investimentos; (g) Políticas Corporativas; (h) Conclusões. A Figura 5 ilustra a proposta final para elaboração do PE.

\begin{tabular}{|c|c|}
\hline Adaptação ao modelo do Hitt, Ireland e Hoskisson (2002) & Ferramentas de Apoio \\
\hline \multicolumn{2}{|l|}{ Fase de diagnóstico de definição de Valores: } \\
\hline Análise Externa & $\begin{array}{l}\text { SWOT, FCS, ESTAP, 5F, } \\
\text { Diamante, AE }\end{array}$ \\
\hline Análise Interna & SWOT, CV, CCV, CAE \\
\hline Intenção Estratégica & FCS \\
\hline Intenção Estratégica, Visão, Missão e Principais Valores & FCS \\
\hline \multicolumn{2}{|l|}{ Formulação de Estratégia: } \\
\hline Estratégia de Nível de Negócios & $\begin{array}{l}\text { SWOT, CV, CCV, BCG, } \\
\text { CAE }\end{array}$ \\
\hline Dinâmica Competitiva & SWOT, 5F \\
\hline Estratégia de Nível Corporativo & $\begin{array}{l}\text { SWOT, FCS, ESTAP, 5F, } \\
\text { Diamante, AE }\end{array}$ \\
\hline Estratégia de Aquisição e Reestruturação & SWOT, FCS, 5F \\
\hline Estratégia Internacional & $\begin{array}{l}\text { SWOT, FCS, ESTAP, 5F, } \\
\text { Diamante, AE }\end{array}$ \\
\hline Estratégia Cooperativa & SWOT, FCS, 5F \\
\hline \multicolumn{2}{|l|}{ Implementação da Estratégia: } \\
\hline Governança Corporativa & CS\&M \\
\hline Estrutura e Controle Organizacionais & - \\
\hline Liderança Estratégica & - \\
\hline Empreendedorismo e Inovação Corporativa & - \\
\hline \multicolumn{2}{|l|}{ Controle e Avaliação } \\
\hline Competitividade Estratégica, Retornos superiores a Média & BSC \\
\hline
\end{tabular}

Quadro 2 - Distribuição de ferramentas ao longo do modelo do Hitt, Ireland e Hoskisson (2002).

Rev. Adm. UFSM, Santa Maria, v. 1, n. 2, p. 225-240, mai./ago. 2008 


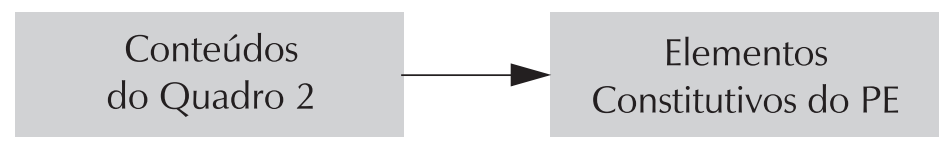

Fonte: Pesquisa teórica.

Figura 5 - Relação do Quadro 2 e a documentação pra o PE.

Evidentemente que o projetista do PE deve cuidar dos alinhamentos qualitativos e quantitativos entre as várias fases.

\section{Conclusões}

No trabalho, mostraram-se contribuições, apresentando as possíveis ligações de ferramentas em nível de abstração mais baixa, com as lógicas maiores que estruturam o pensamento estratégico. Apresentou-se o uso de frames em analogias com as plantas de engenharia na orientação dos passos para elaboração do $\mathrm{PE}$, direcionando as abstrações, promovendo encadeamentos.

Os frames, como o proposto por Hitt, Ireland e Hoskisson (2002), mostram-se visualmente mais ricos que os algoritmos lineares por apresentarem simultaneamente uma visão sinóptica e incremental da estratégia, paralelismos de ações e multidisciplinaridades. Constituise, em essência, num apoio estrutural, funcional e conceitual à memória do decisor, além de se tornar fundamental na elaboração do PE. Na complexidade das organizações no mundo dos negócios atuais, o número de direções que se tem que dirigir o pensar e o disciplinamento da abstração, o frame aparece como um elemento imprescindível ao gestor. Em analogia, as "plantas" de obras estão para as engenharias, assim como os modelos estão para os decisores em administração.

O uso do modelo do Hitt, Ireland e Hoskisson (2002) e a indicação de técnicas de apoio às suas fases, num formato de bricolagem, constituíram uma grade analítica final desse trabalho, que se imagina ter sido alcançado. Essa grade analítica (Quadro 2), embora não se tenha esgotado o número de ferramentas que apóiam o $\mathrm{PE}$, orienta o decisor que efetua o Planejamento Estratégico nas fases conceitual de formulação da estratégia, de implementação e controle. O conjunto de técnicas é enorme e não se pode esgotá-lo nesse artigo e, ainda, há todo um conjunto de nano-técnicas funcionais propostas pelas dimensões do Marketing, Finanças, Produção, análise de Redes, dentre outras.

O que se tem observado é a prática sistemática do "fazer o PE", pelo menos uma vez por ano, e uma (re)visita crítica ao que foi proposto nos anos anteriores, como forma de se avaliar - o que deu e não deu certo - para comemorar, ignorar, punir, premiar ou para aprender. Assim, a documentação via PE passa a ser, no mínimo, um instrumento de aprendizagem organizacional, melhorando a racionalidade e a curva de experiência dos gestores. Sua representação documental faz-se necessária às empresas, pois quanto maiores, mais imprescindível se torna fazê-lo, como uma efetiva carta ou mapa de gestão.

O nome de "última disciplina" se justifica tanto, (a) pela complexidade dessa matéria, lecionada nos últimos períodos dos cursos de Administração, exigindo um esforço superior dos professores e alunos por ligar a esse conteúdo tantos outros, que até então não foram vistos pelos discentes pela vivência - fazendo com que as abordagens sejam, em sua maioria, atos abstratos, amenizados por estudos de casos; quanto (b) por dirigentes que, nos últimos momentos do ano, se projetam no futuro e "depositam fé" nesse instrumento de grande responsabilidade no sentido de dirigir a empresa para o destino almejado.

Rev. Adm. UFSM, Santa Maria, v. 1, n. 2, p. 225-240, mai./ago. 2008 
Como em qualquer previsão, sempre há riscos, é injustiça os autores culparem o PE pelas coisas que não dão certo, devendo, portanto, como conselho de auto-ajuda, pouparemse, dirigir as culpas ao mau comportamento dos eventos. Vale lembrar-se de que as correntes aristotélicas já aconselhavam a não mexer com o futuro, pois, como já diz o dito popular, "o futuro a Deus pertence".

\section{Referências}

AAKER, D. A. Administração estratégica de mercado. Porto Alegre: Bookman, 2001.

BETHELEN, A. Estratégia empresarial: conceitos, processos e administração estratégica. São Paulo: Atlas, 1999.

BULLEN, C. V.; ROCKART, J. F. A primer on critical success factors. Center for information systems research. Sloan School of Management, Massachusetts Institute of Technology, 1981.

DAVID, F. R. Strategic management: concepts \& cases. New Jersey: Prentice Hall, 1998.

FORRESTER, J. W. System dinamics and K12 teachers, in: systems dinamics book. Waltam, MA: Pegasus Communications, 1997.

GHEMAWAT, P. A estratégia e o cenário dos negócios. Porto Alegre: Bookman, 2000.

GONÇALVES, C. A.; REIS, M. T.; GONÇALVES,

C. Administração estratégica: múltiplos enfoques para o sucesso empresarial. Belo Horizonte: UFMG/CEPEAD, 2001.

HITT, M. A.; IRELAND, R. D.; HOSKISSON, R. E. Administração estratégica: competitividade e globalização. São Paulo: Pioneira Thomson Learning, 2002.

KAPLAN, R. S.; NORTON, D. P. A estratégia em ação: balanced scorecard. Rio de Janeiro: Campus, 1997.

KOTLER, P. Administração de marketing: a edição do novo milênio. São Paulo: Prentice Hall, 2000.

MILLER, G. A. The magical number seven, plus or minus two: some limits on our capacity for processing information, The Psychological

Review, v. 63, p. 81-97, 1956.

MINSKY, M. A framework for representing knowledge. In: WINSTON, P. (Ed.). The psychology of computer vision. NewYork: McGraw-Hill, 1975.

MINTZBERG, H. Ascensão e queda do planejamento estratégico. Porto Alegre: Bookman, 2004.

OHMAE, K. The mind of the strategist: the art of japanese business. New York: McGraw-Hill, 1982.

PORTER, M. E. Estratégia competitiva: técnicas para análise de indústria e da concorrência. Rio de Janeiro: Campus, 1986.

PORTER, M. E. Vantagem competitiva. Rio de Janeiro: Campus, 1990.

QUICKMBA. Análise PEST. Disponível em:

$<$ http:/www.quickmba.com>. Acesso em: 12 fev. 2004.

RIES, A.; TROUT, J. Marketing de guerra. São Paulo: McGraw Hill, 1986.

SAS. Strategic Adviser System. BSC - Balanced

Scorecard. Disponível em: < http://sas. interact2000.com.br/bsc.html>. Acesso em: 8 nov. 2004.

SERRA, F. A. R.; TORRES, M. C. S.; TORRES, A. P. Administração estratégica: conceitos, roteiro prático e casos. Rio de Janeiro: Campus, 2004.

STERN, C. W.; STALK JR., G. Estratégia em perspectiva: do Boston Consulting Group. Rio de Janeiro: Campus, 2002. 